\title{
Production of Lipid Microparticles Magnetically Active by a Supercritical Fluid-Based Process
}

\author{
Keti Vezzù, Chiara Campolmi, and Alberto Bertucco \\ DIPIC—Dipartimento di Principi e Impianti di Ingegneria Chimica, via Marzolo, 9, I-35131 Padova, Italy \\ Correspondence should be addressed to Keti Vezzù, keti.vezzu@unipd.it
}

Received 26 November 2008; Revised 16 April 2009; Accepted 26 May 2009

Recommended by Ram B. Gupta

\begin{abstract}
An original technique, based on supercritical $\mathrm{CO}_{2}$ and on the particles from gas saturated solution (PGSS) micronization method, was developed to obtain magnetically active lipid microparticles. Magnetite nanoparticles (MNPs) were encapsulated into triestearin and phosphatidylcholine mixtures to increase their biocompatibility for future applications in the fields of biomedical diagnostics and therapeutic medications. The lipid particles produced were characterized to determine size and size distribution, and to confirm the encapsulation of MNP. The mean size was in the range of $200-800 \mathrm{~nm}$. The possibility to drive these magnetically active particles by an external magnet was demonstrated in a simple apparatus simulating a vessel of the circulatory system. The results obtained indicate that the modified PGSS technique is suitable to produce lipid microparticles with magnetic activity for possible use in medical applications.
\end{abstract}

Copyright () 2009 Keti Vezzù et al. This is an open access article distributed under the Creative Commons Attribution License, which permits unrestricted use, distribution, and reproduction in any medium, provided the original work is properly cited.

\section{Introduction}

For about forty years, nanoparticles with magnetic properties (MNPs) have received great interest in biomedical applications [1], as contrast agents in tomography imaging [2$4]$, drug delivery systems $[5,6]$, and especially in cancer treatment [7], thanks to the possibility to move them to the target site by an external magnetic field, and to accumulate in tissues and specific organs $[8,9]$ without disturbing the physiological activity. For instance, a drug can be carried to the target point, and here released either by the action of enzymes or by changes in physiological conditions such as $\mathrm{pH}$, osmolality, and temperature. On the other hand, in cancer therapy, MNPs are used for their heating effect under the action of an alternate magnetic field of sufficient strength and frequency; the heat is transferred to the surrounding tissue and, if temperature is maintained above the therapeutic threshold of $42{ }^{\circ} \mathrm{C}$ for at least 30 minutes, a significant result can be obtained [7].

In addition, the magnetic response of these nanomaterials disappears after short time when the external field is removed thanks to their paramagnetic behavior, so possible secondary effects are greatly reduced.
In order to inject MNPs into the human body, they must be coated with a suitably biocompatible material. So far, coated MNP systems have been prepared by using different polymers and lipids, such as polylactides, glycerides, fatty acids and $\mathrm{pH}$-sensitive materials, and a number of techniques: high pressure homogenization, warm microemulsion dispersion, polymerization in an acidic medium, and nanoprecipitation $[3,5,8,10-13]$. The coating of magnetite with polymers did not show acute nor subacute toxicity in animals [14]. However, the relatively high temperatures required for their preparation are a severe limit in the application of these techniques for the production of biologically active systems of thermolabile compounds, or when lower melting-point lipids are employed.

In order to overcome this problem, we have developed a technique based on the particles from gas saturated solution process (PGSS) to encapsulate MNPs in lipid nano- and microparticles. PGSS [15] is a flexible solvent-free method operating under milder conditions in the presence of supercritical $\mathrm{CO}_{2}$. Our modified PGSS technique takes advantage of an inert gas suitably fed to the atomization system [16]. According to the process we are proposing, the MNPcontaining lipid suspension is melted under $\mathrm{CO}_{2}$ pressure 
at moderate temperature, and then micronized through a nozzle using air/nitrogen as an atomization promoter, in order to obtain magnetically active lipid particles of size that can be adjusted by tuning the operative variables (pressure, temperatures, and inert gas to melt rate ratio).

The MNP encapsulation was checked by electron microscopy. The size of the lipid particles and the encapsulation efficiency were determined by Light Scattering and Thermogravimetric Analysis techniques, respectively. The ability to move them by an external magnetic field was checked in a home-made apparatus, simulating a vessel of the circulatory system.

\section{Materials and Experimental Set-Up}

2.1. Materials. Nanoparticles of magnetite $\left(\mathrm{Fe}_{3} \mathrm{O}_{4}\right)$, which is stable and displays low toxicity (LD50 in rats $=400 \mathrm{mg} / \mathrm{kg}$ ) [14], were used in the experiments. Their size was between $10-30 \mathrm{~nm}$.

The lipids mixtures were based on triestearin, phosphatidylcholine, and oleic acid. Suitable amounts of ammonium hydroxide $\left(\mathrm{NH}_{4} \mathrm{OH}\right)$, dichloromethane (DCM), and Tween 20 (a surfactant) were added.

All of the materials above were purchased from SigmaAldrich (Italy). Carbon dioxide $\left(\mathrm{CO}_{2}\right)$, nitrogen, and air were supplied by Sapio (Monza, Italy) and helium by Air Liquid (Italy).

Distilled and milliQ water was produced in our laboratory.

2.2. Conditioning of Magnetic Nanoparticles. The MNPs were wetted with oleic acid to increase their lipophilicity. Accordingly, $0.5 \mathrm{~g}$ of MNP were loaded in a glass vial, and $12.5 \mathrm{~mL}$ of deionized water and $0.024 \mathrm{~mol}$ of $\mathrm{NH}_{4} \mathrm{OH}$ were added. Oxygen was removed with a helium flux, then the suspension was heated at $90{ }^{\circ} \mathrm{C}$ for 30 minutes under stirring. After the addition of $0.038 \mathrm{~mL}$ of oleic acid, the mixture was kept at $90^{\circ} \mathrm{C}$ for 10 minutes, and then slowly cooled down. The MNPs coated with oleic acid were dried under vacuum.

2.3. Preparation of Mixture Between Lipids and MNPs. The MNPs were dispersed in triestearin fine powder to obtain a mixture with desired and uniform composition. When phosphatidylcholine was used, it was dissolved in DCM. The triestearin-MNP mixture was added to this solution. The solvent was completely removed: by evaporation at room temperature overnight (8 hours) and under vacuum.

2.4. Apparatus and Procedure-PGSS. The apparatus to carry out our modified PGSS process is basically composed by a thermostated mixing chamber (MC), a piston pump (P2), an expansion section including the nozzle (CE), and a particle collection system. A schematic is shown in Figure 1. Details are reported elsewhere [16].

A suitable amount of the mixture to be processed is loaded in the mixing chamber, where it is contacted with supercritical $\mathrm{CO}_{2}$ for the required time at selected temperature and pressure conditions. Then, it is pumped through the nozzle $(\mathrm{U})$, where microparticles are produced. The micronization is promoted by two air/nitrogen auxiliary streams, one just before the nozzle (supplied by a cylinder at $200 \mathrm{bar}$ ), the other one in the collection chamber (supplied by a compressor at 10 bar). The particles are collected on a metallic filter $(F)$ for further characterization.

The temperatures of all the plant sections are carefully controlled to prevent undesired precipitation of solids. The temperature set-point values depend on the viscosity of mixtures used.

In all the experiments completely dried particles were always collected from the filter.

\subsection{Apparatus and Procedure-Simulated Circulatory Vessel.} This equipment, sketched in Figure 2, is made up of a glass tube with inner diameter of $3.5 \mathrm{~mm}(\mathrm{~F})$, a peristaltic pump (A), and a system for particles injection (B). The aqueous suspension flow rate $(0-14 \mathrm{~mm} / \mathrm{s})$ can be controlled by varying the voltage $(G)$ applied to the pump $(A)$. Water is loaded in beaker $\mathrm{C}$ and the aqueous suspension is collected in beaker $\mathrm{D}$.

A magnetic field of 900 Gauss (in the pipe center) is maintained by a permanent magnet, shaped as a ring, so that the field lines are parallel to the flow direction.

About $6 \mathrm{mg}$ of lipid particles containing MNPs were dispersed in $1.2 \mathrm{~mL}$ of milliQ water by ultrasounds (CP104, Vetrotecnica) for 20 minutes in an ice bath. About $1 \mathrm{~mL}$ of particle suspension was injected in the water flow by a precision syringe (B). After about 10 minutes, the pump was turned off. The amount of particles in suspension was determined by UV-vis measurement: the scattering peak is correlated to the concentration of particles in the suspension, according to a procedure developed elsewhere [17]. The mass of particles trapped by the magnetic field was obtained by the difference between the injected and collected amounts.

\subsection{Particle Characterization}

2.6.1. Differential Scanning Calorimetry (DSC). DSC spectra were performed using a Q10P/PDSC (TA Instruments) equipped with a pressure cell system that allows operating at high temperature (up to $80^{\circ} \mathrm{C}$ ) and at different pressures (from 1 up to 60 bar). About $2 \mathrm{mg}$ of substance, both unprocessed material and particles produced by the experiments, were analyzed at ambient pressure to study the effect of the micronization process. The unprocessed mixtures were also analyzed under $\mathrm{CO}_{2}$ pressure (from 1 to 60 bar) to study the plasticization effect.

The heating and cooling rates were always $1{ }^{\circ} \mathrm{C} /$ minute, a value found to be suitable to obtain accurate and reproducible results.

2.6.2. Light Scattering (LS). Particle size analysis was performed using a Nicomp 380/Dynamic Light Scattering, Submicron Particle Sizer (Particle Sizing Systems Santa BarbaraCalifornia). $1 \mathrm{mg}$ of lipid-coated MNPs was suspended in $5 \mathrm{~mL}$ of deionized water (for triestearin-phosphatidylcholine 


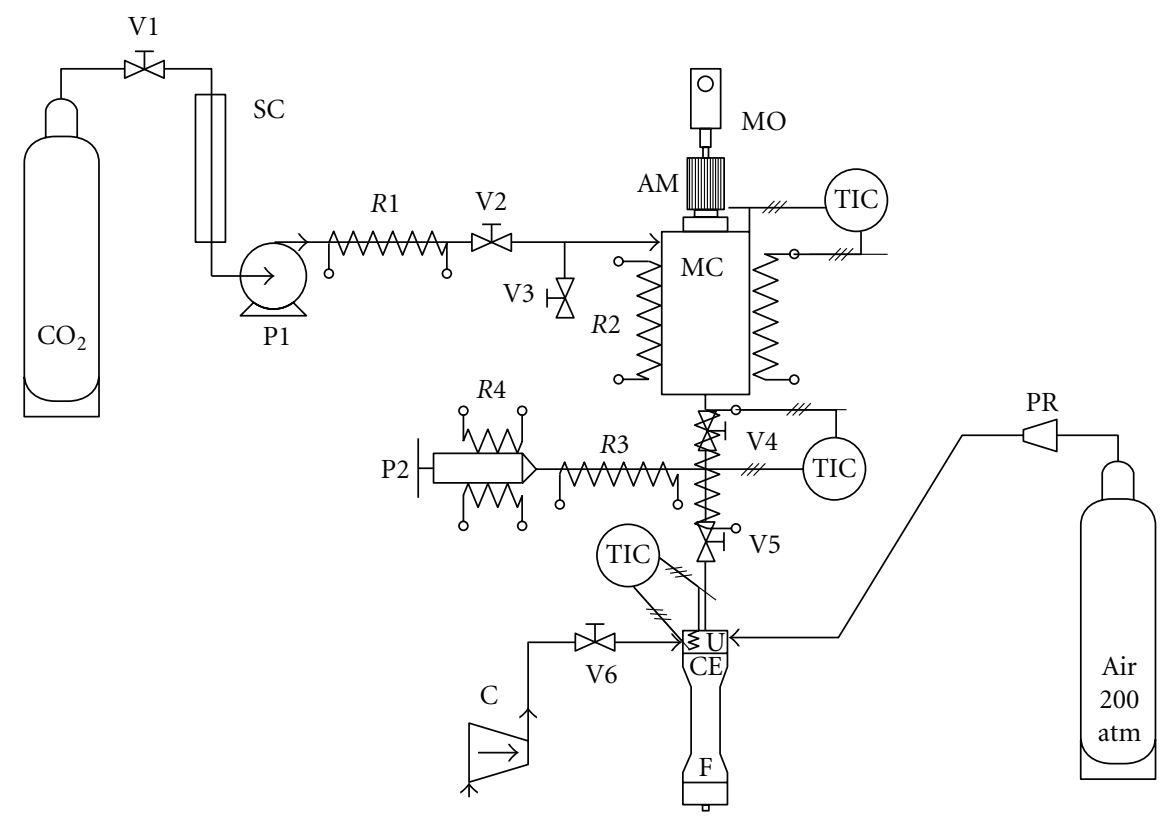

FIGURE 1: Schematic of the apparatus to carry out our modified-PGSS technique: MO, electric motor; AM, stirrer; MC, mixing chamber; U, nozzle; CE, expansion chamber; F, filter; R1, R2, R3, and R4, electric resistances; SC, heater exchanger; P1, pump; P2, manual syringe pump; V1, V2, V3, V4, V5, and V6, on-off valves; PR, pressure reducer; C, air compressor; TIC, temperature indicator and controller.

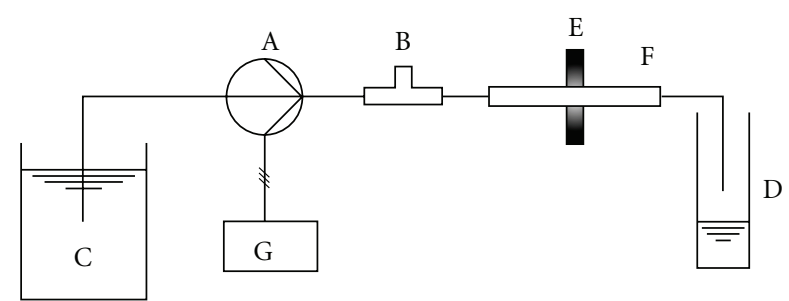

FIGURE 2: Schematic of the equipment simulating a circulatory vessel: A, peristaltic pump; B, injection system; C, D, beakers; E, permanent magnet; F, glass tube; $\mathrm{G}$, tension regulator.

particles), or in Tween 20 solution (for triestearin ones). The suspension was sonicated in an ice bath for 20 minutes before analysis.

2.6.3. Transmission Microscopy (TEM) and electron diffraction. About 5-10 milligrams of particles were sonicated in isopropanol by a point sonicator $(1$ minute and 70 Watt at $20 \mathrm{kHz}$ ). Drops of this suspension were deposited on a cupper circular grid of 300 mesh, the solvent was evaporated for 12 hours at room temperature, then the samples were analyzed by a Jeol 3010 Microscope. With the same instrument also the diffraction measurements were performed.

2.6.4. Thermogravimetric Analysis (TGA). Few milligrams of particles were loaded in the aluminum pan of a thermogravimetric balance (TA Instruments). The sample was heated in air from room temperature to $900{ }^{\circ} \mathrm{C}$, with a rate of $500{ }^{\circ} \mathrm{C} /$ minute. The temperature was kept constant for 5 minutes to ensure complete lipid burning.

\section{Results}

3.1. DSC Measurements. Similar results were obtained from the DSC measurements on the starting mixtures and on the particles produced, with values of melting temperatures basically unaffected by the PGSS treatment and by the presence of MNPs (see Table 1). However, the addition of phosphatidylcholine to triestearin significantly reduced the enthalpy of fusion.

Calorimetric measurements under $\mathrm{CO}_{2}$ pressure were carried out on triestearin-magnetite and triestearinphosphatidylcholine-magnetite mixtures to study the effect of $\mathrm{CO}_{2}$ on the melting temperature. As shown in Figure 3, where the DSC spectra of triestearin-phosphatidylcholine with $10 \%(\mathrm{w} / \mathrm{w})$ of $\mathrm{MNP}$ are reported as a function of $\mathrm{CO}_{2}$ pressure around the melting zone, by raising the pressure both the melting temperature and the enthalpy of fusion decreased. However, these changes were independent of the MNP concentration, similarly to the results obtained at ambient pressure.

The reduction of melting temperature due to $\mathrm{CO}_{2}$ pressure is both a common feature and a requirement to perform successfully any PGSS-like process [18]. Our DSC measurements under $\mathrm{CO}_{2}$ pressure gave information to optimize the process experimental conditions, such as the temperature in the mixing chamber and that at the nozzle, in order to avoid undesired solidification. The operative conditions finally selected are summarized in Table 2. 
TABLE 1: DSC spectra measured at ambient pressure for triestearin-magnetite and triestearin-phosphatidylcholine-magnetite starting mixtures, and for particles produced by the modified-PGSS process.

\begin{tabular}{|c|c|c|c|c|c|c|c|}
\hline \multirow[b]{2}{*}{ Composition } & \multirow[b]{2}{*}{$\begin{array}{c}\% \\
\text { magnetite }\end{array}$} & \multicolumn{4}{|c|}{ Mixtures } & \multicolumn{2}{|c|}{ Particles } \\
\hline & & $\begin{array}{l}T_{\text {melt }} \\
{\left[{ }^{\circ} \mathrm{C}\right]}\end{array}$ & $\begin{array}{c}\Delta H_{\text {melt }} \\
{[\mathrm{J} / \mathrm{g}]}\end{array}$ & $\begin{array}{c}T_{\text {sol }} \\
{\left[{ }^{\circ} \mathrm{C}\right]}\end{array}$ & $\begin{array}{c}\Delta H_{\text {sol }} \\
{[\mathrm{J} / \mathrm{g}]}\end{array}$ & $\begin{array}{l}T_{\text {melt }} \\
{\left[{ }^{\circ} \mathrm{C}\right]}\end{array}$ & $\begin{array}{c}\Delta H_{\text {melt }} \\
{[\mathrm{J} / \mathrm{g}]}\end{array}$ \\
\hline \multirow{4}{*}{ Triestearin-magnetite } & 0 & 67.4 & 126 & 48.6 & 105 & 67.2 & 144 \\
\hline & 1 & 66.6 & 123 & 49.0 & 114 & 67.2 & 144 \\
\hline & 5 & 67.0 & 117 & 48.8 & 110 & 67.2 & 138 \\
\hline & 10 & 66.9 & 122 & 48.9 & 107 & 67.0 & 125 \\
\hline \multirow{3}{*}{ Triestearin-treated magnetite } & 1 & 66.9 & 127 & 48.9 & 116 & 66.9 & 110 \\
\hline & 5 & 67.0 & 118 & 48.8 & 102 & 67.1 & 140 \\
\hline & 10 & 66.4 & 110 & 48.8 & 96 & 66.9 & 155 \\
\hline \multirow{4}{*}{ Triestearin-phosphatidylcholine-magnetite } & 0 & 68.7 & 73 & 51.0 & 45 & 66.3 & 69 \\
\hline & 1 & 68.8 & 60 & 48.9 & 40 & 66.9 & 78 \\
\hline & 5 & 68.1 & 100 & 49.3 & 63 & 66.8 & 69 \\
\hline & 10 & 67.5 & 62 & 49.3 & 40 & 67.0 & 75 \\
\hline
\end{tabular}

TABle 2: Process operative conditions.

\begin{tabular}{|c|c|c|c|c|c|}
\hline Composition & $\% \mathrm{MNP}$ & $\begin{array}{c}P \text { mixing } \\
{[\text { bar }]}\end{array}$ & $\begin{array}{c}T \text { mixing } \\
{\left[{ }^{\circ} \mathrm{C}\right]}\end{array}$ & $\begin{array}{c}T \text { pump } \\
{\left[{ }^{\circ} \mathrm{C}\right]}\end{array}$ & $\begin{array}{c}T \text { nozzle } \\
{\left[{ }^{\circ} \mathrm{C}\right]}\end{array}$ \\
\hline Triestearin & $0,1,5,10$ & $150-160$ & 60 & 55 & 60 \\
\hline Triestearin-Phosphatidylcholine & $0,1,5,10$ & $150-160$ & 65 & 60 & 65 \\
\hline
\end{tabular}

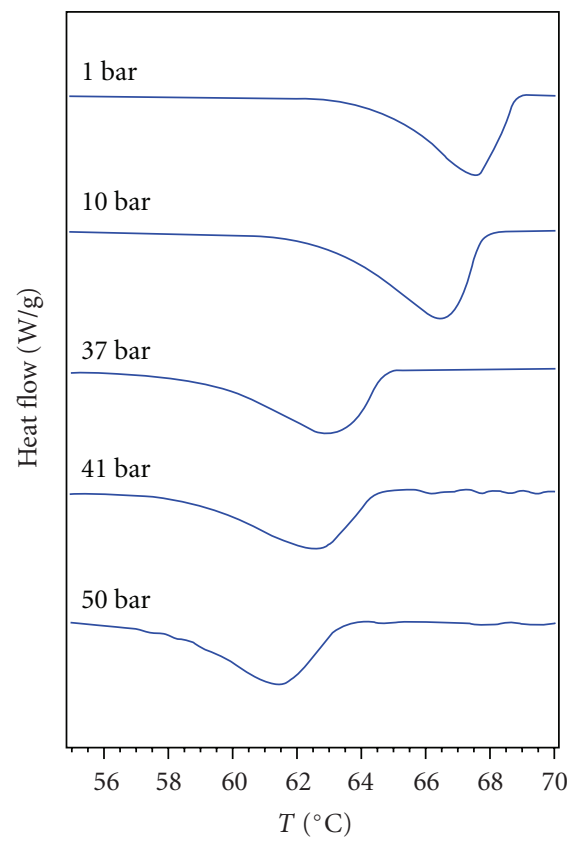

FIGURE 3: DSC spectra of triestearin-phosphatidylcholine-10\% $(\mathrm{w} / \mathrm{w})$ magnetite mixture as a function of pressure.

3.2. LS Measurements. The lipid particles obtained were analyzed by LS to determine their average size and size distribution. Results are listed in Table 3.

The measurements showed bimodal and trimodal distributions, with one peak always at $890 \mathrm{~nm}$, and the two others (if present) around $200 \mathrm{~nm}$ and around $400 \mathrm{~nm}$. The larger peak is probably due to agglomerated particles not broken by sonication, as revealed by the residual error analysis (data not shown). By using a stronger sonicator, the residual error was slightly reduced, without affecting the average size values.

The non-unimodal distribution could be partly due to the manual injection system of the MNP-lipid mixture in the nozzle. However, we recall that bimodal distributions are not unusual, as they were obtained also with other lipid mixtures [19], and they can be predicted by crystallization models taking into account agglomeration phenomena $[19,20]$.

According to Table 3, the average size values were not affected by the MNP concentration, and also the oleic acid pretreatment had negligible influence. It is also noteworthy that, when using a triestearin-phosphatidylcholine mixture $(1: 1 \mathrm{w} / \mathrm{w})$, a higher fraction of particles with size lower than $500 \mathrm{~nm}$ was produced. This fact may be due to the surfactant effect of phosphatidylcholine, which reduces the average drop size out of the nozzle.

It can be concluded that the size of the particles produced by the modified-PGSS technique presently developed is compatible to their possible application as carriers for biomedical diagnostics and therapeutic medications.

3.3. TEM Analysis. As shown in Figure 4 lipid particles of different color were obtained depending on the amount of magnetite used in the preparation of the initial mixture: they get darker and darker when increasing this amount, thus suggesting the encapsulation of more magnetite [21].

The encapsulation was confirmed by TEM analysis. Examples of TEM micrographs are reported in Figures 5(a), $5(\mathrm{~b})$, and 5(c). Here, it is possible to distinguish magnetite 


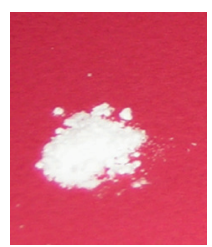

(a)

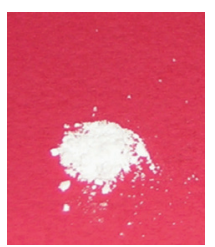

(b)

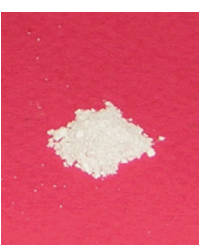

(c)

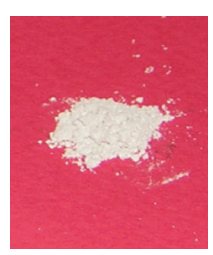

(d)

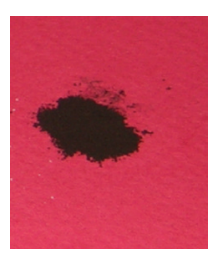

(e)

FIGURE 4: Pictures of particles produced by the modified-PGSS process starting from: (a) triestearin, (b) triestearin $+1 \%$ magnetite, (c) triestearin $+5 \%$ magnetite, $(\mathrm{d})$ triestearin $+10 \%$ magnetite, and (e) magnetite powder.

TABLE 3: Light Scattering measurements on the lipid nano- and microparticles.

\begin{tabular}{|c|c|c|c|c|c|c|c|}
\hline \multirow{2}{*}{ Composition } & \multirow{2}{*}{$\%$ magnetite } & \multicolumn{2}{|c|}{$1^{\circ}$ peak } & \multicolumn{2}{|c|}{$2^{\circ}$ peak } & \multicolumn{2}{|c|}{$3^{\circ}$ peak } \\
\hline & & $\varnothing[\mathrm{nm}]$ & $\%$ & $\varnothing[\mathrm{nm}]$ & $\%$ & $\varnothing[\mathrm{nm}]$ & $\%$ \\
\hline \multirow{4}{*}{ Triestearin-magnetite } & 0 & $240 \pm 100$ & 25 & & & $876 \pm 200$ & 75 \\
\hline & 1 & $200 \pm 80$ & 13 & $400 \pm 200$ & 14 & $870 \pm 200$ & 73 \\
\hline & 5 & $245 \pm 100$ & 14 & & & $882 \pm 200$ & 86 \\
\hline & 10 & $160 \pm 50$ & 8 & $250 \pm 90$ & 5 & $883 \pm 200$ & 87 \\
\hline \multirow{3}{*}{ Triestearin-magnetite treated with oleic acid } & 1 & & & $200 \pm 80$ & 10 & $887 \pm 200$ & 90 \\
\hline & 5 & & & $250 \pm 85$ & 15 & $887 \pm 200$ & 85 \\
\hline & 10 & $160 \pm 50$ & 8 & $254 \pm 110$ & 5 & $884 \pm 200$ & 87 \\
\hline \multirow{4}{*}{ Triestearin-phosphatidylcholine-magnetite } & 0 & $119 \pm 55$ & 34 & $500 \pm 200$ & 66 & & \\
\hline & 1 & $55 \pm 20$ & 49 & $200 \pm 80$ & 15 & $885 \pm 200$ & 37 \\
\hline & 5 & $80 \pm 25$ & 40 & $250 \pm 85$ & 30 & $885 \pm 200$ & 30 \\
\hline & 10 & $55 \pm 20$ & 44 & $200 \pm 80$ & 15 & $885 \pm 200$ & 46 \\
\hline
\end{tabular}

(darker spheres) from lipids, which look gray. In particular, the arrows in Figure 5(c) indicate two nanospheres of magnetite inside a single lipid nanoparticle.

The size of the particles in Figure 5 is of about $20-50 \mathrm{~nm}$; in fact, it was decided to perform the TEM analysis on the fraction of smaller particles only, to avoid side effects due to the strength of the magnetic field of the instrument.

To confirm that the dark spots are magnetite nanoparticles, the same samples were analyzed by electronic diffraction. A result is displayed in Figure 5(d), where the circular alignment of white spots can be observed, corresponding to the diffraction due to crystalline material. Such a crystallinity must be ascribed to the magnetite and not to the lipids, because in the modified-PGSS, process the cooling step is so rapid not to permit any crystallization of the lipidic fraction.

3.4. TGA Measurements. By TGA analysis, the amount of MNPs encapsulated in the lipid particles was evaluated. During the TGA heating process, at $200-300{ }^{\circ} \mathrm{C}$ the iron contained in magnetite $\left(\mathrm{Fe}_{3} \mathrm{O}_{4}\right)$ is oxidized to $\mathrm{Fe}_{2} \mathrm{O}_{3}$, so the percent of magnetite encapsulated can be evaluated by:

$$
\begin{aligned}
\text { \%encapsulation } & =\frac{m_{\mathrm{Fe}_{3} \mathrm{O}_{4}}}{m_{\mathrm{Fe}_{3} \mathrm{O}_{4} \text {, theoretical }}} \cdot 100 \\
\text { with : } m_{\mathrm{Fe}_{2} \mathrm{O}_{3}} & =\mathrm{NPLM}_{\mathrm{res}}-\mathrm{SLN}_{\mathrm{res}} \\
m_{\mathrm{Fe}_{3} \mathrm{O}_{4}} & =\frac{m_{\mathrm{Fe}_{2} \mathrm{O}_{3}}}{\mathrm{PM}_{\mathrm{Fe}_{2} \mathrm{O}_{3}}} \cdot \frac{2}{3} \cdot \mathrm{PM}_{\mathrm{Fe}_{3} \mathrm{O}_{4}},
\end{aligned}
$$

where $m_{\mathrm{Fe}_{2} \mathrm{O}_{3}}, m_{\mathrm{Fe}_{3} \mathrm{O}_{4}}$ are the mass of ferric oxide and magnetite analyzed, NPLM res $_{\text {and }}$ SLN $\mathrm{N}_{\text {res }}$ are the mass of lipid particles with and without magnetite remaining after the combustion process, $\mathrm{PM}_{\mathrm{Fe}_{2} \mathrm{O}_{3}}$ and $\mathrm{PM}_{\mathrm{Fe}_{3} \mathrm{O}_{4}}$ are the molecular

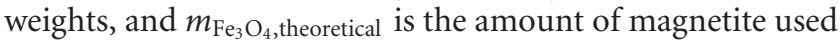
in the initial mixture.

The TGA results, summarized in Table 4, show that the amount of magnetite encapsulated was less than that loaded in the mixing chamber. The encapsulation efficiency is independent of the kind of lipid, and increases with the concentration of magnetite in the initial mixture. This last fact suggests that efficiency is probably due to wall deposition of MNP, and that it can be increased by using and apparatus with lower surface-to-volume ratio (i.e., by scaling up the process). Anyway, our values are lower than those given by Okassa et al. [22], who employed the double emulsion method and the emulsion evaporation process.

From the TGA results, the magnetic saturation $\left(\mathrm{MS}_{(\mathrm{NPLM})}\right)$ can be calculated as [23]:

$$
\mathrm{MS}_{(\mathrm{NPLM})}=\frac{\%_{\text {encapsulation }} \cdot \mathrm{MS}_{(\text {magnetite })}}{100}
$$

where $\mathrm{MS}_{\text {(magnetite) }}$ is the saturation magnetization of MNP. It is possible to assume that MS of $10-30 \mathrm{~nm}$ magnetite nanospheres is about $60 \mathrm{emu} / \mathrm{g}$, a value in between those given by literature $[23,24]$. Also the saturation magnetization of the lipid particles is reported in Table 4.

According to the saturation magnetization, it is possible to calculate the force applied to a coated magnetite particle in a fixed magnetic gradient field. 


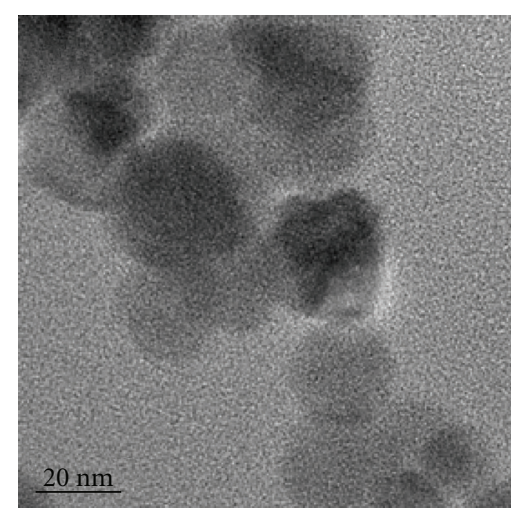

(a)

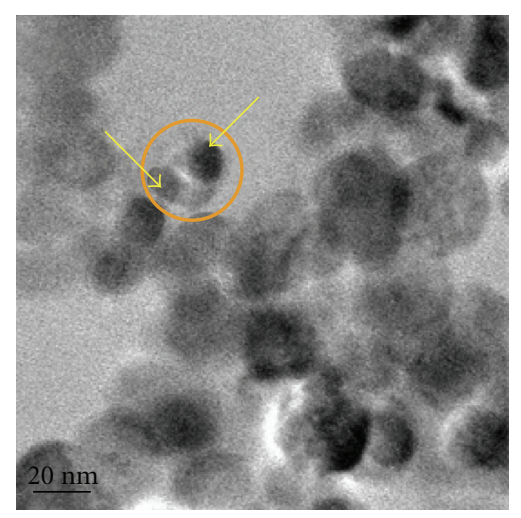

(c)

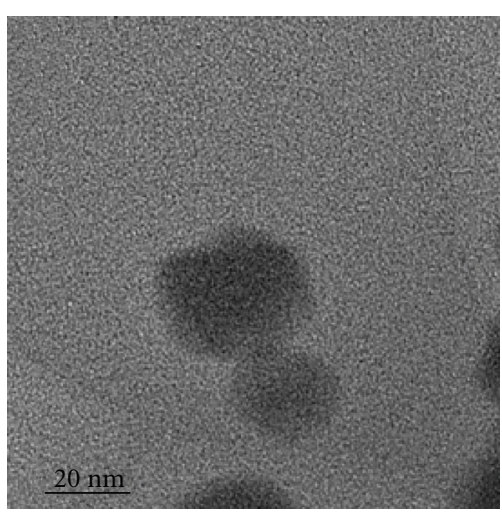

(b)

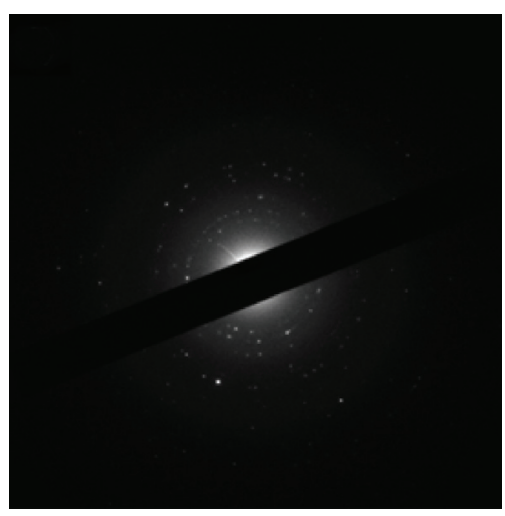

(d)

FIGURE 5: Micrographs of triestearin-5\% magnetite produced by the modified-PGSS technique: (a), (b), (c) TEM images. Two MNPs enclosed in a lipid particle are evidenced by the yellow arrows; $(\mathrm{d})$ spot of diffraction of electron beam on magnetite nanoparticles.

TABLE 4: Efficiency of magnetite nanoparticles encapsulation in the lipid particles and their saturation magnetization.

\begin{tabular}{lcccc}
\hline Composition & $\begin{array}{c}\% \mathrm{Fe}_{3} \mathrm{O}_{4} \\
\text { theoretical }\end{array}$ & $\begin{array}{c}\% \mathrm{Fe}_{3} \mathrm{O}_{4} \\
\text { encapsulated }\end{array}$ & $\begin{array}{c}\% \\
\text { encapsulation }\end{array}$ & $\begin{array}{c}\mathrm{MS}_{(\mathrm{NPLM})} \\
{[\mathrm{emu} / \mathrm{g}]}\end{array}$ \\
\hline Triestearin & 5 & 1.7 & $36 \%$ & 1.02 \\
Triestearin-phosphatidylcholine & 1 & 0.22 & $22 \%$ & 0.13 \\
Triestearin-phosphatidylcholine & 5 & 1.9 & $40 \%$ & 1.14 \\
\hline
\end{tabular}

3.5. Capture of Particles by an External Magnetic Field. The possibility to trap the microparticles produced by the modified-PGSS technique was studied by the apparatus in Figure 2 according to the procedure outlined earlier.

The results obtained are displayed in Figure 6. In particular we note that the entrapment depends on the amount of magnetite encapsulated (Figure 6(a)) and on the fluid velocity (Figure 6(b)). Solid lipid (pure triestearin) particles yield negligible capture values, within the experimental error $( \pm 2 \%)$, thus excluding any affinity between the tube wall and the lipid particles, and confirming that entrapment was due to the effect of the external magnet field only.

The encapsulation efficiency is positively affected by the magnetite concentration in the initial mixture (Figure 6(a)), as already seen from TGA measurements (Table 4), whereas the fluid velocity has a negative effect.

Finally, from Figure 7 it can be clearly seen that the entrapment is independent of the lipid matrix of the nanoand microparticles.

As shown in the Appendix, the particles are trapped not as single particles but as aggregates (ferrofluids, [23]), which are formed by the magnetization of MNP due to the magnetic field applied.

In our case, the treatment of magnetite with oleic acid did not increase the entrapment efficiency, as suggested by Okassa et al. [22]. These results could be explained by the lower oleic acid amount we have used, with respect to other authors: for instance,Farridi-Majidi et al. [25], who 


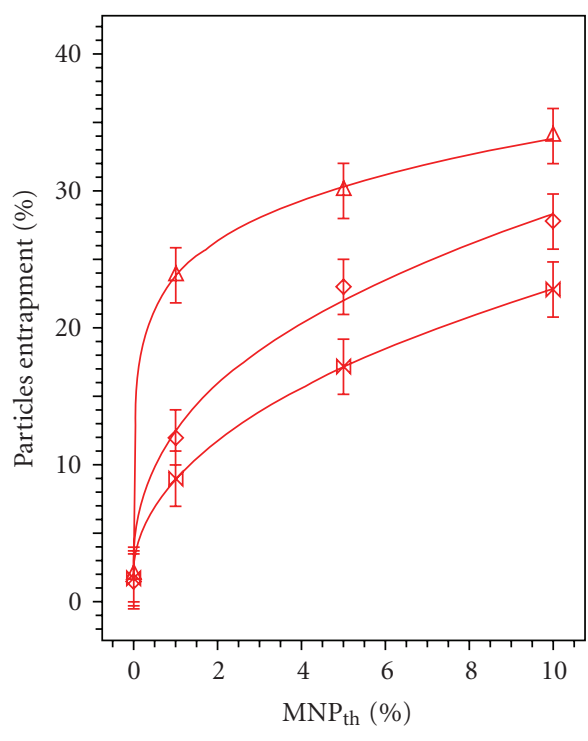

$\triangle 3 \mathrm{~mm} / \mathrm{s}$

$\diamond 8 \mathrm{~mm} / \mathrm{s}$

$\bowtie 14 \mathrm{~mm} / \mathrm{s}$

(a)

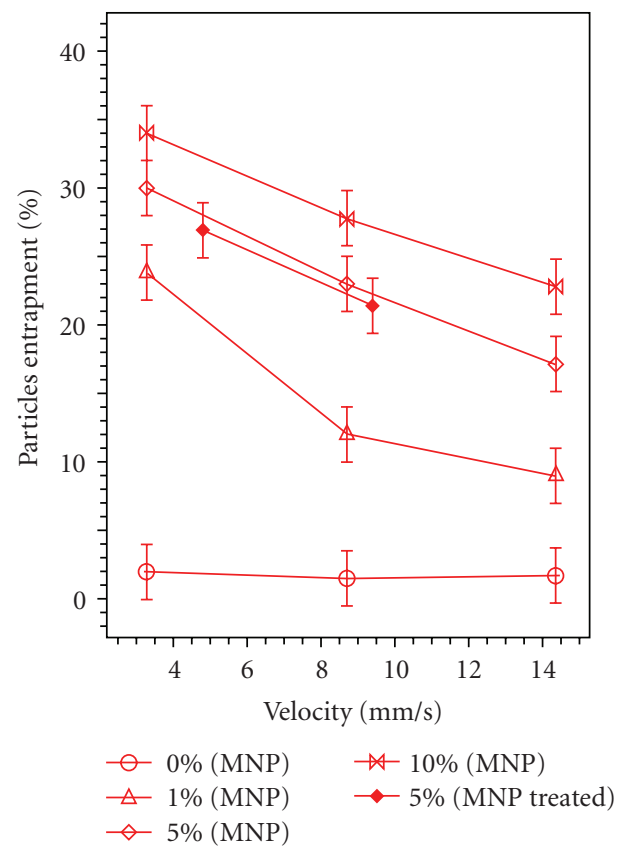

(b)

FIGURE 6: Entrapment of triestearin-magnetite particles as a function of: (a) percentage of magnetite in the starting lipid mixture and (b) fluid velocity.

used more oleic acid per unit MNP, found an increased encapsulation efficiency and also a larger particle size, an effect we tried to avoid.

We point out that the magnetic field applied (900 G) was lower than the maximum value applicable to the human body (8000 G, [24]). Therefore, the lipid magnetic particles

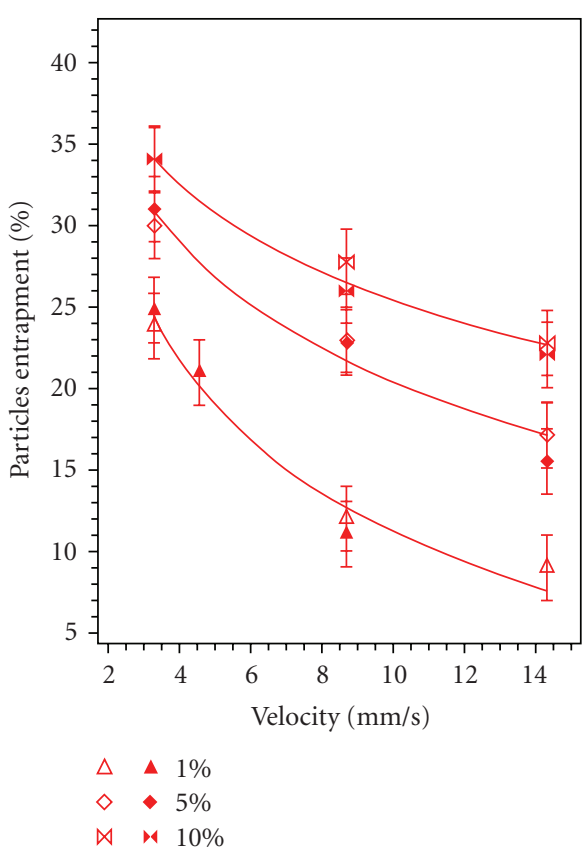

FIGURE 7: Entrapment of triestearin-magnetite (void symbols) and triestearin-phosphatidylcholine-magnetite (full symbol) particles as a function of fluid velocity and concentration of magnetite in the initial mixture.

produced by our modified-PGSS process have properties which are suitable for future use in biomedical application.

\section{Conclusions}

Nanoparticles of magnetite were coated with lipids to form lipid nano- and microparticles by a modified-PGSS technique carried out at moderate temperature.

Small size lipid particles with magnetic activity were produced: more than $50 \%$ of them had diameter less than $500 \mathrm{~nm}$. The encapsulation efficiency of magnetite nanoparticles was about $30 \%$ and increased with the concentration of magnetite in the initial mixture.

The possibility to trap the lipid-coated magnetite nanoparticles by an external magnet was demonstrated in a simple apparatus, with results comparable to those found in literature for polymeric coatings: about $30 \%$ of the particles trapped, when using a magnetic field value compatible with applications to the human body.

The coating of magnetite nanoparticles with lipids by the modified-PGSS process presently developed provide materials which may be interesting for diagnostic and therapeutic applications.

\section{Appendix}

\section{Force Balance in the Circulatory Vessel Apparatus}

A number of works are reported in literature about the capture of MNP by an external magnetic field, but they 
were usually carried out on magnetic nanoparticles without coating. On the other hand, Asmatulu et al. [24] simulated the drug delivery process employing a tube of $0.6 \mathrm{~mm}$ diameter, a magnetic field gradient of about $900 \mathrm{G} / \mathrm{m}$, and magnetic nanoparticles coated with different kinds of polymers. Saturation magnetization was in the range of 1$80 \mathrm{emu} / \mathrm{g}$ and particle diameters were between 0.5 and $7 \mu \mathrm{m}$. In experimental conditions similar to ours (fluid velocity of $5 \mathrm{~mm} / \mathrm{s}$, particles diameter of $0.5-1 \mu \mathrm{m}$ with a saturation magnetization of $1 \mathrm{emu} / \mathrm{g}$ ), these authors could capture $20 \%$ of the particles, a value comparable with ours.

These results can be checked considering the two main forces acting on the system under analysis, that is, the magnetic $\left(F_{\text {mag }}\right)$ and the drag force $\left(F_{\text {idr }}\right)$. If the inertial and gravity forces are neglected due to the small particle size, the condition to stop the particles is:

$$
F_{\text {mag }}>F_{\text {idr. }} \text {. }
$$

If the interactions between the wall of the tube and the particles are neglected and the flow is assumed to be laminar [7], the drag force can be expressed by the Stokes law:

$$
F_{\mathrm{idr}}=-3 \cdot \pi \cdot \eta \cdot d \cdot v_{r}
$$

where $\eta$ is the fluid viscosity $(0.016 \mathrm{~kg} /(\mathrm{ms}),[7]), d$ is the particle diameter $(\mathrm{m}), v_{p}$ and $v_{0}$ are the velocity of the particle and fluid $(\mathrm{m} / \mathrm{s})$, respectively, and $v_{r}\left(=v_{p}-v_{0}\right)$ is the relative velocity of the particle $\left(v_{p}\right)$ to the fluid $\left(v_{0}\right)$. On the other hand, the magnetic force can be written as

$$
F_{\mathrm{mag}}=\mu_{0} \cdot M \cdot\left(\frac{d H}{d s}\right) \cdot V_{\mathrm{par}}
$$

where $\mu_{0}$ is the vacuum magnetic permeability $\left(1.26 \cdot 10^{-26}\right.$ $\mathrm{W} / \mathrm{Am}), M$ the magnetization of the magnetite coated lipid nanoparticles $(\mathrm{A} / \mathrm{m}), V_{\text {par }}$ the volume of a single particle (assumed of spherical shape) and $(d H / d s)$ the magnetic field gradient along the $s$-direction (in our case, the radial one). This last value was calculated from experimental measurement of magnet's field and the magnetization by using

$$
M=\chi H
$$

with $\chi$ (magnetic susceptibility for the magnetite nanoparticles) equal to $3 \cdot 10^{6}$, an average value among those found in literature $\left(1 \cdot 10^{6}-5.7 \cdot 10^{6},[24]\right)$.

Considering the symmetry of the permanent magnet, a particle can be stopped by the magnetic field if

$$
v_{r}=\frac{F_{\mathrm{mag}}}{3 \pi \eta d}
$$

By applying (A5), it can be seen that the relative velocity in the center of magnet is close to zero, because here the magnetic force is negligible. Far from the pipe axis, it can be calculated that $F_{\text {mag }}$ is always smaller than $F_{\text {idr }}$. This is in disagreement with the experimental results (up to $30 \%$ of particles stopped, as shown in Figures 6 and 7). Apparently, the formation of particles aggregates due to the reciprocal magnetic forces is responsible for results like ours, so that particles (called ferrofluids) are formed. Xu et al. [23] showed that the magnetic force acting on pure magnetic nanoparticles was higher than the hydrodynamic one, and the formation of this structure was the reason for entrapment.

\section{Acknowledgment}

The support of the Italian Minister of Research (MIUR) under PRIN 05 program is gratefully acknowledged.

\section{References}

[1] A. Ito, M. Shinkai, H. Honda, and T. Kobayashi, "Medical application of functionalized magnetic nanoparticles," Journal of Bioscience and Bioengineering, vol. 100, no. 1, pp. 1-11, 2005.

[2] L. F. Gamarra, G. E. S. Brito, W. M. Pontuschka, E. Amaro, A. H. C. Parma, and G. F. Goya, "Biocompatible superparamagnetic iron oxide nanoparticles used for contrast agents: a structural and magnetic study," Journal of Magnetism and Magnetic Materials, vol. 289, pp. 439-441, 2005.

[3] D. K. Kim, Y. Zhang, J. Kehr, T. Klason, B. Bjelke, and M. Muhammed, "Characterization and MRI study of surfactantcoated superparamagnetic nanoparticles administered into the rat brain," Journal of Magnetism and Magnetic Materials, vol. 225, no. 1-2, pp. 256-261, 2001.

[4] L. Babes, B. Denizot, G. Tanguy, J. J. Le Jeune, and P. Jallet, "Synthesis of iron oxide nanoparticles used as MRI contrast agents: a parametric study," Journal of Colloid and Interface Science, vol. 212, no. 2, pp. 474-482, 1999.

[5] P. Chattopadhyay and R. B. Gupta, "Supercritical $\mathrm{CO}_{2}$ based production of magnetically responsive micro- and nanoparticles for drug targeting," Industrial and Engineering Chemistry Research, vol. 41, no. 24, pp. 6049-6058, 2002.

[6] A. S. Lübbe, C. Alexiou, and C. Bergemann, "Clinical applications of magnetic drug targeting," Journal of Surgical Research, vol. 95, no. 2, pp. 200-206, 2001.

[7] O. Rotariu and N. J. C. Strachan, "Modelling magnetic carrier particle targeting in the tumor microvasculature for cancer treatment," Journal of Magnetism and Magnetic Materials, vol. 293, no. 1, pp. 639-646, 2005.

[8] S. C. Yang, L. F. Lu, Y. Cai, J. B. Zhu, B. W. Liang, and C. Z. Yang, "Body distribution in mice of intravenously injected camptothecin solid lipid nanoparticles and targeting effect on brain," Journal of Controlled Release, vol. 59, no. 3, pp. 299307, 1999.

[9] S. E. Dunn, A. G. A. Coombes, M. C. Garnett, S. S. Davis, M. C. Davies, and L. Illum, "In vitro cell interaction and in vivo biodistribution of poly(lactide-co-glycolide) nanospheres surface modified by poloxamer and poloxamine copolymers," Journal of Controlled Release, vol. 44, no. 1, pp. 65-76, 1997.

[10] H. Pardoe, W. Chua-anusorn, T. G. St. Pierre, and J. Dobson, "Structural and magnetic properties of nanoscale iron oxide particles synthesized in the presence of dextran or polyvinyl alcohol," Journal of Magnetism and Magnetic Materials, vol. 225, no. 1-2, pp. 41-46, 2001.

[11] J. Lee, T. Isobe, and M. Senna, "Preparation of ultrafine $\mathrm{Fe}_{3} \mathrm{O}_{4}$ particles by precipitation in the presence of PVA at high $\mathrm{pH}$," Journal of Colloid and Interface Science, vol. 177, no. 2, pp. 490494, 1996. 
[12] P. A. Dresco, V. S. Zaitsev, R. J. Gambino, and B. Chu, "Preparation and properties of magnetite and polymer magnetite nanoparticles," Langmuir, vol. 15, no. 6, pp. 1945-1951, 1999.

[13] U. T. Lam, R. Mammucari, and N. R. Foster, "Production of magnetically and ph responsive biodevices by dense gas technology," in Proceedings of the 11th European Meeting on Supercritical Fluids: Reactions, Materials and Natural Products Processing, Barcellona, Spain, May 2008.

[14] A. Iannone, R. L. Magin, T. Walczak, et al., "Blood clearance of dextran magnetite particles determined by a noninvasive in vivo ESR method," Magnetic Resonance in Medicine, vol. 22, no. 2, pp. 435-442, 1991.

[15] J. Jung and M. Perrut, "Particle design using supercritical fluids: literature and patent survey," Journal of Supercritical Fluids, vol. 20, no. 3, pp. 179-219, 2001.

[16] A. Bertucco, P. Caliceti, and N. Elvassore, "Process for the production of nano-particles," WO2007028421.

[17] A. Striolo, N. Elvassore, T. Parton, and A. Bertucco, "Relationship between volume expansion, solvent-power, and precipitation in GAS processes," AIChE Journal, vol. 49, no. 10, pp. 2671-2679, 2003.

[18] E. Weidner, V. Wiesmet, Ž. Knez, and M. Škerget, "Phase equilibrium (solid-liquid-gas) in polyethyleneglycol-carbon dioxide systems," Journal of Supercritical Fluids, vol. 10, no. 3, pp. 139-147, 1997.

[19] J. Li, M. Rodrigues, A. Paiva, H. A. Matos, and E. G. de Azevedo, "Modeling of the PGSS process by crystallization and atomization," AIChE Journal, vol. 51, no. 8, pp. 2343-2357, 2005.

[20] N. Elvassore, T. Parton, A. Bertucco, and V. Di Noto, "Kinetics of particle formation in the gas antisolvent precipitation process," AIChE Journal, vol. 49, no. 4, pp. 859-868, 2003.

[21] M. Igartua, P. Saulnier, B. Heurtault, et al., "Development and characterization of solid lipid nanoparticles loaded with magnetite," International Journal of Pharmaceutics, vol. 233, no. 1-2, pp. 149-157, 2002.

[22] L. Ngaboni Okassa, H. Marchais, L. Douziech-Eyrolles, et al., "Development and characterization of sub-micron poly(d,l-lactide-co-glycolide) particles loaded with magnetite/maghemite nanoparticles," International Journal of Pharmaceutics, vol. 302, no. 1-2, pp. 187-196, 2005.

[23] Z. Z. Xu, C. C. Wang, W. L. Yang, Y. H. Deng, and S. $\mathrm{K} . \mathrm{Fu}$, "Encapsulation of nanosized magnetic iron oxide by polyacrylamide via inverse miniemulsion polymerization," Journal of Magnetism and Magnetic Materials, vol. 277, no. 1-2, pp. 136-143, 2004.

[24] R. Asmatulu, M. A. Zalich, R. O. Claus, and J. S. Riffle, "Synthesis, characterization and targeting of biodegradable magnetic nanocomposite particles by external magnetic fields," Journal of Magnetism and Magnetic Materials, vol. 292, pp. 108-119, 2005.

[25] R. Faridi-Majidi, N. Sharifi-Sanjani, and F. Agend, "Encapsulation of magnetic nanoparticles with polystyrene via emulsifier-free miniemulsion polymerization," Thin Solid Films, vol. 515, no. 1, pp. 368-374, 2006. 

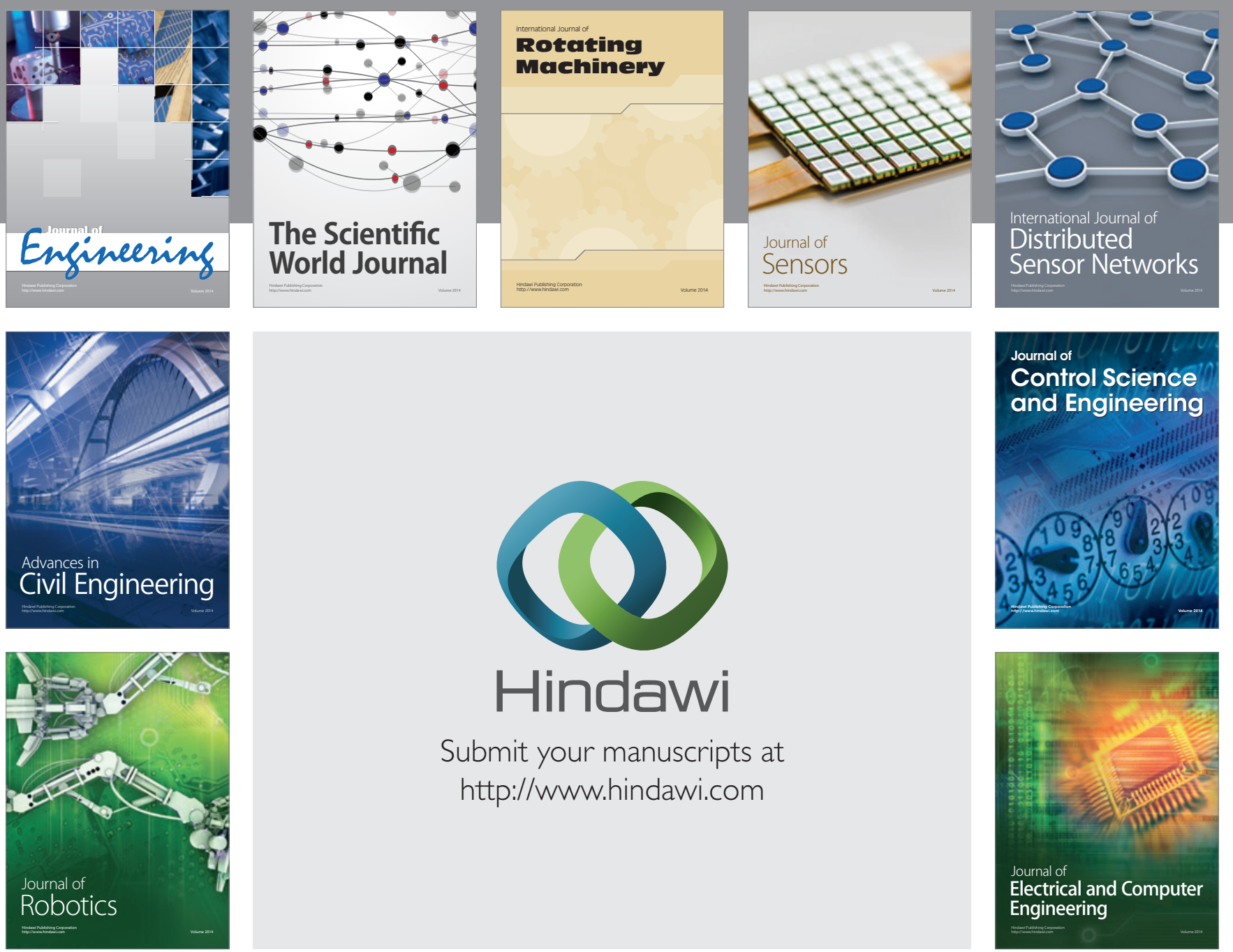

Submit your manuscripts at

http://www.hindawi.com
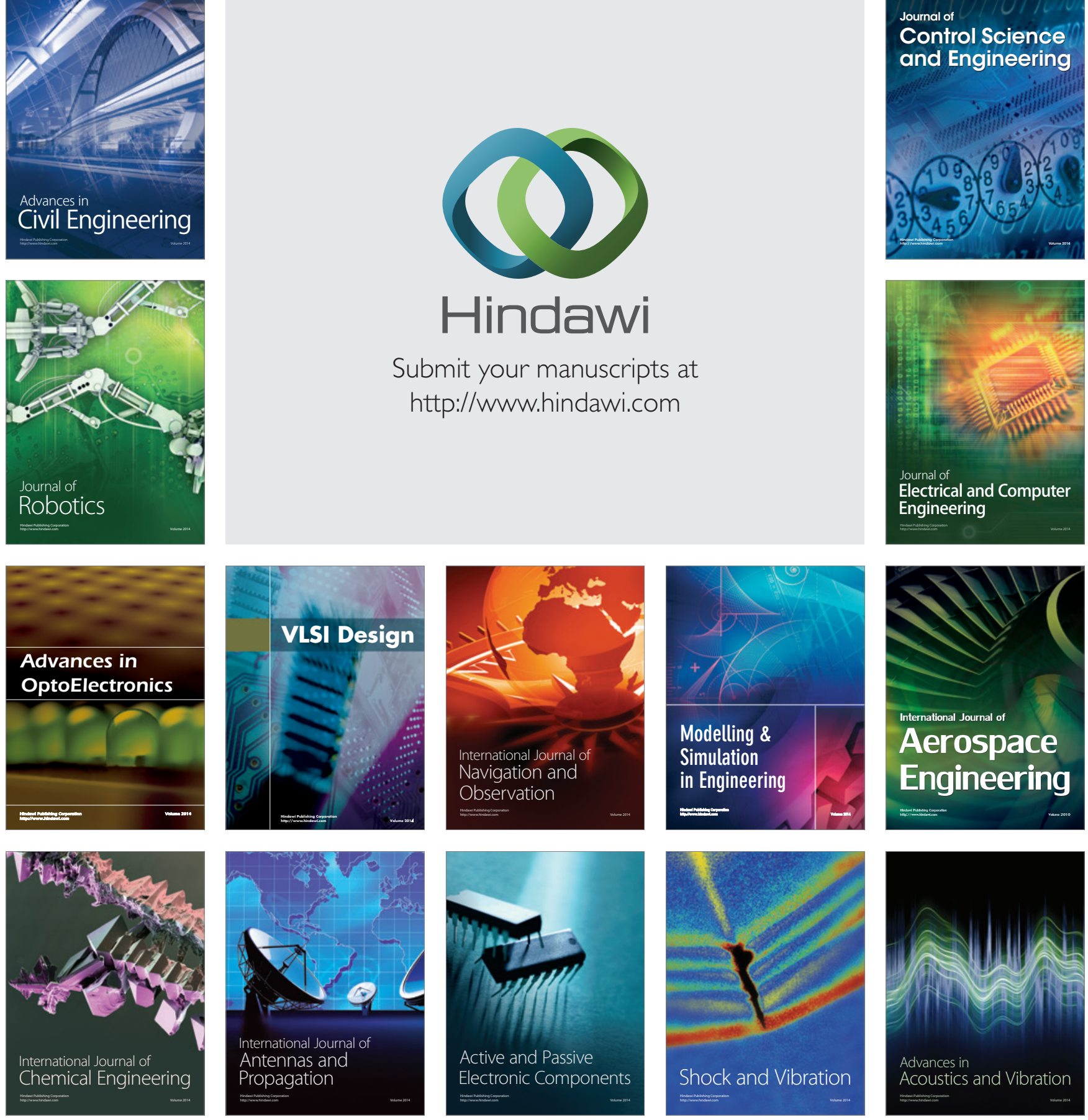